\title{
The effects of punishment on food pellet discrimination
}

\section{WILLIAM F. VITULLI, University of South Alabama, Mobile,} Ala. 36608

Rats were trained on a multiple schedule of reinforcement. The reinforcers were Noyes sucrose and standard food pellets. The onset of a shock of approximately $.40 \mathrm{~mA}$ and $50 \mathrm{msec}$ was paired, simultaneously and consistently, with one type of pellet. Removal of shock on alternate blocks of sessions resulted in contrast effects between rates following sucrose and standard pellets. The presence of shock suppressed postreinforcement rates of responding following the shockpaired pellet. Response rate decrements were less following the pellet type not paired with shock during the same session.

Acquired discriminative properties of aversive events such as shock or intense noise have been studied by Holz \& Azrin (1961 and 1962). Their paradigm was to associate the aversive stimulus with the occurrence of positive primary reinforcement. The focus of analysis in these and similar studies was on the subsequent discriminative control exerted by the aversive event. The purpose of the present investigation was to study conditions which might produce aversive properties of positive primary reinforcers.

Is was predicted that distinctive food pellets can function as punishing stimuli when paired with shock in a multiple schedule of reinforcement. Hake $\&$ Azrin (1965) delivered a shock to a pigeon at the end of a 15 -sec change in illumination (CS). The CS suppressed the bird's response rate when presented without shock in later sessions. Since the CS was response contingent it was referred to as conditioned punishment. Food pellets, in addition to their reinforcing properties, have discriminative properties (Cruse, Vitulli, \& Dertke, 1966). It appeared that a food pellet could also function as a punishing stimulus.

\section{METHOD}

Two male Holtzman albino rats (S3 and S4) with no previous training were used. The animals were approximately three months old and weighed between 260 and $275 \mathrm{~g}$ under conditions of free food and water at the beginning of the experiment. They were reduced to $85 \%$ of their free-feeding weights and were maintained at from $75 \%$ to $85 \%$ of free-feeding weight throughout the experiment.

A Grason-Stadler one-lever rat chamber was used. The chamber received pellets from two Davis pellet dispensers. One dispenser presented Noyes stock 45-mg standard food pellets. The other dispenser presented Noyes stock $45-\mathrm{mg}$ sucrose food pellets. The dispensers were mounted on a wall directly above and outside of the experimental enclosure. A Y-shaped surgical tubing arrangement extended from the dispensers to the food hopper in the chamber. A third dispenser (Grason-Stadler) was located inside the experimental enclosure and contained no pellets. The Grason dispenser operated whenever either of the Davis dispensers operated to mask their possible differential sounds. A Foringer white-noise generator was connected in series with the chamber speaker. Its continual operation masked possible extraneous sounds occurring outside of the experimental enclosure. A Grason-Stadler shock generator was the source of scrambled electric shock stimuli. Conventional programming and recording equipment was used.
After the animals were reduced to $85 \%$ of their free-feeding weights, S3 was magazine trained with standard pellets and S4 was magazine trained with sucrose pellets. Both organisms were then rewarded for every lever response by the same type of pellet which was used during magazine training. The response ratio was gradually increased for both rats to an FR 30 over the following 12 sessions. After five sessions on FR 30 with standard pellets for S3 and sucrose pellets for S4, each $S$ received both types of pellets under a multiple FR 30-FR 30 schedule. At this point the only accompanying stimuli for FR 30 components in the multiple schedule were different type food pellets. After 10 sessions a mean shock intensity of $.55 \mathrm{~mA}$ and $100 \mathrm{msec}$ was paired simultaneously with the occasion of each standard pellet in the multiple FR 30-FR 30 schedule for S3. The onset of the shock occurred at the same time as the dropping of the food pellet in the hopper. A mean-shock intensity of $.54 \mathrm{~mA}$ and $80 \mathrm{msec}$ was paired simultaneously with the occasion of each sucrose pellet in the multiple FR 30-FR 30 schedule for S4. Again, the onset of the shock occurred at the same time as the dropping of the food pellet in the hopper. During blocks of sessions in which shock was presented, each $S$ received both types of pellets. One type of pellet was consistently associated with shock and the other pellet was never associated with shock.

Daily sessions lasted for an average of 60 pellets or $1 \mathrm{~h}$, whichever came first, for each $S$. The pellet sequence under the multiple schedule was random and proportionally stratified for each session so that both animals received an average of $50 \%$ sucrose and $50 \%$ standard pellets per session (Vitulli, 1967, p. 496). Blocks of sessions alternated with respect to the presence or absence of shock correlated with the respective pellet type per $S$. The total program for mean-shock intensity and duration per pellet for $\mathrm{S} 3$ and $\mathrm{S} 4$ is presented in Table 1.

\section{RESULTS}

Figure 1 presents stable absolute rates for the terminal three sessions partitioned from each block for S3 and S4. Sessions in which shock was paired with standard pellets for S3 and

Table 1

Pellet Type, Mean Shock Intensity and Duration per Successive Blocks of Sessions in the Multiple FR 30-FR 30 for S 3 and S 4.

\begin{tabular}{|c|c|c|c|}
\hline \multirow{2}{*}{$\begin{array}{l}\text { Blocks of } \\
\text { Sessions }\end{array}$} & \multirow{2}{*}{$\begin{array}{l}\text { No. of } \\
\text { Sessions }\end{array}$} & \multicolumn{2}{|c|}{$\begin{array}{c}\text { Shock Intensity \& Duration with } \\
\text { Pellet Type }\end{array}$} \\
\hline & & S 3: Standard & S 4: Sucrose \\
\hline 1 & 10 & No Shock & No Shock \\
\hline 2 & 33 & $.55 \mathrm{~mA}-100 \mathrm{msec}$ & $.54 \mathrm{~mA}-80 \mathrm{msec}$ \\
\hline 3 & 10 & No Shock & No Shock \\
\hline 4 & 10 & $.33 \mathrm{~mA}-60 \mathrm{msec}$ & $.30 \mathrm{~mA}-50 \mathrm{msec}$ \\
\hline 5 & 5 & No Shock & No Shock \\
\hline 6 & 5 & $.40 \mathrm{~mA}-50 \mathrm{msec}$ & $.40 \mathrm{~mA}-50 \mathrm{msec}$ \\
\hline 7 & 5 & No Shock & No Shock \\
\hline 8 & 5 & $.40 \mathrm{~mA}-50 \mathrm{msec}$ & $.40 \mathrm{~mA}-50 \mathrm{msec}$ \\
\hline 9 & 5 & No Shock & No Shock \\
\hline 10 & 5 & $.40 \mathrm{~mA}-50 \mathrm{msec}$ & $.40 \mathrm{~mA}-50 \mathrm{msec}$ \\
\hline 11 & 5 & No Shock & No Shock \\
\hline 12 & 5 & $.40 \mathrm{~mA}-50 \mathrm{msec}$ & $.40 \mathrm{~mA}-50 \mathrm{msec}$ \\
\hline 13 & 5 & No Shock & No Shock \\
\hline 14 & 5 & $.40 \mathrm{~mA}-50 \mathrm{msec}$ & $.40 \mathrm{~mA}-50 \mathrm{msec}$ \\
\hline
\end{tabular}




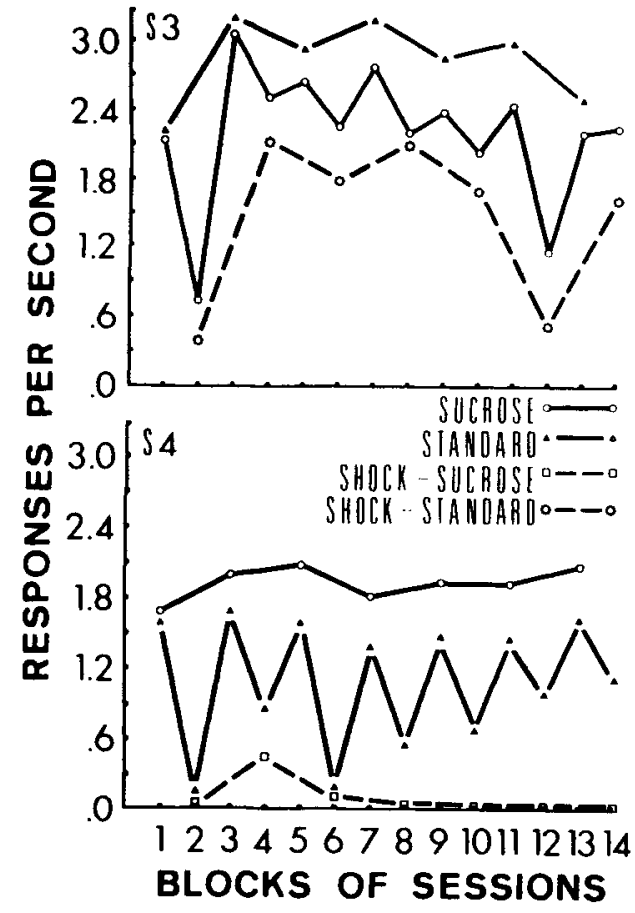

Fig. 1. Stable absolute response rates following sucrose and standard pellets in the mult FR 30-FR 30 schedule for the terminal three sessions of each successive block for $\$ 3$ and $\$ 4$.

sucrose pellets for S4 indicate considerably lower postreinforcement rates as compared with rates following the opposing pellet type. Sessions in which shock was not delivered indicate considerably higher postreinforcement rates following pellets previously paired with shock in prior sessions. Pellets never associated with shock (sucrose for S3 and standard for S4) provide operant baselines against which shock and postshock rates may be compared.

\section{DISCUSSION}

The results were inversely related to the original prediction. Association of an aversive stimulus with positive primary reinforcement tended to increase rates following the reinforcer when the aversive stimulus was removed. There was no evidence that a pellet became a conditioned punisher under the conditions of the present study. The temporal relations between the onset of the shock and the occurrence of a pellet in the hopper warrant further research.

Behavioral contrast describes the postshock session rates produced between the pellets. Reynolds (1961) defined contrast as "when the change in the rate of responding during the presentation of one stimulus is in a direction away from the rate of responding generated during the presentation of the other stimulus [p. 57]." The presence of response-contingent shock associated with a distinctive pellet had punishing effects. Rates of responding in nonshock sessions tended to rise in direct proportion to the degree of previous suppression.

\section{REFERENCES}

CRUSE, D. B., VITULLI, W. F., \& DERTKE, M. Discriminative and reinforcing properties of two types of food pellets. Journal of the Experimental Analysis of Behavior, 1966, 9, 293-303.

HAKE, D. F., \& AZRIN, N. H. Conditioned punishment. Journal of the Experimental Analysis of Behavior, 1965, 8, 279-293.

HOLZ, W. C., \& AZRIN, N. H. Discriminative properties of punishment. Journal of the Experimental Analysis of Behavior, 1961, 4, 225-232.

HOLZ, W. C., \& AZRIN, N. H. Interactions between the discriminative and aversive properties of punishment. Journal of the Experimental Analy sis of Behavior, 1962, 5, 229-234.

REYNOLDS, G. S. Behavioral contrast. Journal of the Experimental Analysis of Behavior, 1961, 4, 57-71.

VITULLI, W. F. Stimulus properties of varied food concentrations. Psychonomic Science, 1967, 9, 495-496. NOTE

1. Equipment was funded in part by the Research Committee of the University of South Alabama. Appreciation is expressed to the following students from the Work Study Program for their invaluable assistance: Robert Battles, Kathryn Buntyn, and Daniel Koch. An extended analysis of this problem appears in the Journal of Psychology, 1969, 71, 177-183.

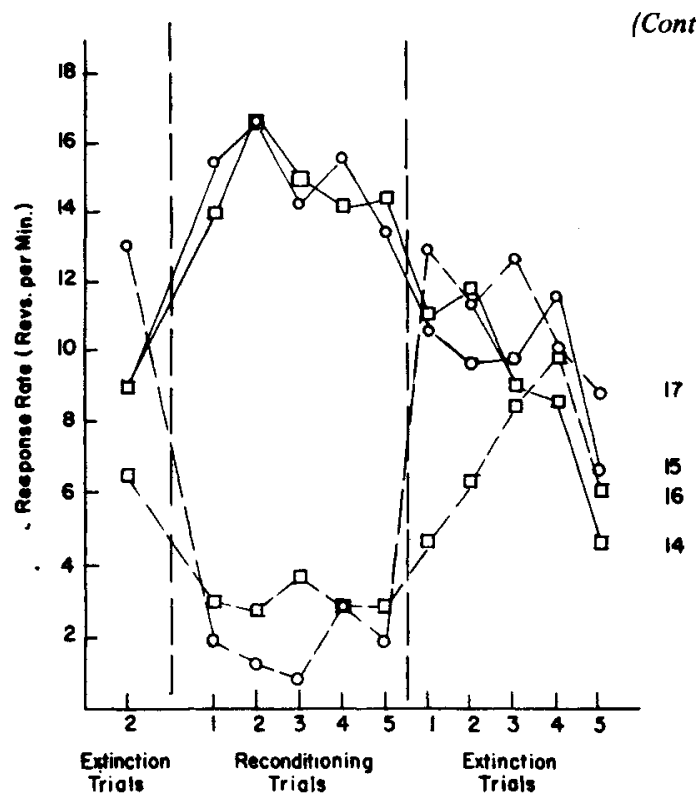

Fig. 2. Following two extinction trials (Fig. 1) all Ss were given five reconditioning trials followed by five extinction trials.
(Continued from page 131)

components of the increase in wheel running by food-deprived rats, Connally (1968) supported the findings of Duda and Bolles. Connally used 1-h test periods followed by immediate feeding and found no effects of learning but a significant linear correlation (.52) between body-weight deficit and wheel running. Even with 1-h periods it is impossible to control contingencies of reinforcement, i.e., what response is made by $\mathrm{S}$ immediately prior to presentation of reinforcement.

In the present study, reinforcement was contingent solely upon the response to be conditioned, either running or not-running. With control of this contingency, the wheelrunning response by food-deprived rats is seen to be clearly modifiable in an operant conditioning paradigm.

\section{REFERENCES}

CONNALLY, R. E. Drive and habit components of running activity by the rat. Psychonomic Science, in press.

DUDA, J. J., \& BOLLES, R. C. Effects of prior deprivation, current deprivation and weight loss in the activity of the hungry rat. Joumal of Comparative and Physiological Psychology, 1963, 56, 569-571.

$$
\text { NOTE }
$$

1. The author extends his appreciation to Miss Judee VanDaam of Temple Buell College for her competent assistance in this research. 